\title{
Double-blind comparison of single doses of DS103-282, baclofen and placebo for suppression of spasticity
}

\author{
N H ASS A N A D D L M C LELLA N \\ From the Department of Medicine, University of Southampton and Wessex Neurological Centre, \\ Southampton General Hospital, Southampton
}

SUMMARY Twelve spastic patients received single oral doses of a new anti-spastic drug DS103-282 (Sandoz) $6 \mathrm{mg}$, baclofen $20 \mathrm{mg}$, and placebo on three separate days. Passive stretch responses were measured before administration and for four hours afterwards. DS103-282 was more effective than baclofen, and both drugs were more effective than placebo. Analysis of the recordings confirmed that DS103-282 had a specific effect upon stretch reflexes independent of its effect on resting muscle tone. Its action appeared at 30 to 45 minutes after ingestion, with maximum activity at 60-90 minutes. Unwanted effects of DS103-282 were drowsiness and (in one case) potentiation of antihypertensive therapy.

DS103-282 (Sandoz) is a centrally acting benzothiadiazol derivative (5-chloro-4 [2-imidazole-2-ylamino] -2, 1, 3-benzothiadiazole), which in preliminary clinical trials has been shown to reduce muscle tone in mean daily oral doses of $4.9 \mathrm{mg} .{ }^{12}$ We present an analysis of its effect upon slow stretch responses in 12 spastic patients.

\section{Method}

Subjects studied Twelve adult volunteers were studied. Their clinical details are summarised in table 1. Pregnant women and patients with heart disease were excluded from the study.

Preparation of subjects Antispastic medication was discontinued for three days before the study in the three patients who were routinely taking it. They had a light lunch, consisting of a salad and fruit juice and after control measurements an

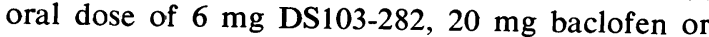
matching placebo capsule was given. The patient then sat in a comfortable dental chair for the next $3 \frac{1}{2}$ or $4 \mathrm{~h}$ and assessments were made 30,45 and $60 \mathrm{~min}$ after ingestion and thereafter at 30 min intervals. The laboratory was quiet and the

Address for reprint requests: Dr DL McLellan, Southampton General Hospital, Tremona Road, Southampton SO9 4XY.

Accepted 30 July 1980 patients were encouraged to empty bowel and bladder at the first intimation of a desire to do so. Observations The patients were asked to report any symptoms during the course of the afternoon. Pulse and blood pressure were measured with each assessment, using a coiled-spring sphygmanometer. Measurement of muscle tone Surface electromyograms were recorded from the biceps and triceps muscles (three patients) and quadriceps and hamstring muscles (10 patients) as appropriate for the patients' condition, using Medelec contact preamplifiers feeding into Medelec AAK Mark 3 amplifiers, the integral filters of which were set $3 \mathrm{~dB}$ down at $16 \mathrm{~Hz}$ and $800 \mathrm{~Hz}$. The angle of the relevant knee or elbow joint was recorded using a conducting-plastic potentiometer fixed to the patient with a parallelogram linkage and calibrated with a protractor. The EMG signals and the potentiometer signal were recorded on an FM tape recorder (Bell and Howell, VR3000). The potentiometer signal was displayed as a cross on an oscilloscope screen and could be made to follow a target signal by passive movement of the joint by the observer. The target moved sinusoidally so that to follow it the joint had to be flexed and extended from $90-135^{\circ}$ in a sinusoidal motion; the electromyographic responses to 32 cycles of movement at three different repetition rates $(0 \cdot 26$, 0.52 and $0.78 \mathrm{~Hz}$ ) were recorded. 
Table 1 Patients tested, showing identity of tablets considered to show the greatest antispastic effect by comparison of 18 graphs for each subject judged independently by 2 observers (see text)

\begin{tabular}{lllll}
\hline Subject & Age & Sex & Diagnosis & Best result \\
\hline 1 & 18 & M & Idiopathic spastic paresis & Placebo \\
2 & 48 & M & Idiopathic spastic paresis & DS103-282 \\
3 & 52 & M & Idiopathic spastic paresis & DS103-282 \\
4 & 29 & M & Idiopathic spastic paresis & DS103-282 \\
5 & 50 & M & Hemiparesis and cervical spondylosis & Baclofen \\
6 & 72 & M & Multiple sclerosis & DS103-282 \\
7 & 15 & Traumatic brain stem lesion & DS103-282 \\
8 & 53 & M & Hemiparesis (stroke) & Baclofen \\
9 & 31 & M & Idiopathic spastic paresis & Baclofen \\
10 & 62 & Hemiparesis in infancy & DS103-282 \\
11 & 18 & Memiparesis in infancy & Multiple sclerosis & DS103-282 \\
12 & 41 & & &
\end{tabular}

The EMG signals were fed also into electronic integrators that could be re-set according to the phase of the potentiometer cycle (this system has been described previously by McLellan et $a l .^{3}$ This enabled the EMG to be integrated cycle by cycle and displayed as a series of spikes by a pen recorder, the height of the spike indicating the amount of EMG activity collected in each epoch. Stretching and shortening phases of this cycle were analysed separately. The effects of the drugs upon activity evoked by stretch could thus be compared with their effects upon the activity occurring during passive shortening of the muscle. Finally, the signals were full-wave rectified and then averaged with a Datalab DL4000 digital averager using the potentiometer signal to trigger the averager at the same point in each cycle. In this way a profile of the EMG activity during the cycle could be established and the position of the peak response in relation to the stretching cycle could be identified.

\section{Results}

Integrated EMG scores

The amounts of integrated EMG recorded during passive stretching and shortening phases showed considerable inter-individual variation. Thus, if means and standard deviations were calculated for each set of recordings across the whole patient group, no significant trends could be discerned. Initially, the integrated EMG scores for the stretching phase (corrected for the EMG recording gain) and then for the shortening phase were plotted against time for each set of observations. Lengthening activity and shortening activity was analysed for flexor and extensor muscles. For example, a patient whose quadriceps and hamstring muscle had been analysed at the three repetition rates $(0.26,0.52$ and $0.78 \mathrm{~Hz})$ generated 12 curves for each afternoon's recordings (six for each muscle), making 36 curves in all. Before any code was broken, the three sets from the three separate days were ranked by us independently as showing the most, next best and least evidence of an antispastic drug effect.

The results are given in tables 1 and 2 . When the scores of the two assessors were averaged, DS103-282 was the most effective antispastic agent in eight cases, baclofen in three cases and placebo in one case.

DS103-282 had similar effects upon extensor and flexor muscles. Each observer ranked the drugs in the same order, but NH favoured DS103-282 more highly than DLMcL, especially in extensor muscles. In discussion after this analysis was com-

Table 2 Comparative efficacy of DS103-282, baclofen and placebo in 11 patients. Each figure is the mean number of patients (ranked by the two observers after visual inspection of the records) responding to the various treatments indicated in the left-hand column. Patient 7 had a shortening reaction and only his stretching data are included; data from patient 10 , whose recording was terminated when he reacted adversely to DS103-282 are omitted. Stretch responses were suppressed more effectively by DS103-282 than by baclofen in the doses used. In contrast, the suppressive effect of baclofen upon EMG activity during muscle shortening was similar to the effect of DS103-282.

\begin{tabular}{|c|c|c|c|c|c|}
\hline \multirow[t]{2}{*}{ Drug } & \multirow{2}{*}{$\begin{array}{l}\text { Grade of } \\
\text { response }\end{array}$} & \multicolumn{2}{|c|}{ Flexor mucles } & \multicolumn{2}{|c|}{ Extensor muscles } \\
\hline & & Stre & Shortening & Stret & Shortening \\
\hline $\begin{array}{l}\text { DS103- } \\
2826 \mathrm{mg}\end{array}$ & $\begin{array}{l}\text { Best } \\
\text { Next } \\
\text { Worst }\end{array}$ & $\begin{array}{l}6.5 \\
3.5 \\
1.0\end{array}$ & $\begin{array}{l}3.0 \\
4.0 \\
3.0\end{array}$ & $\begin{array}{l}7.0 \\
2.0 \\
2.0\end{array}$ & $\begin{array}{l}4.5 \\
3.5 \\
2.0\end{array}$ \\
\hline $\begin{array}{c}\text { Baclofen } \\
20 \mathrm{mg}\end{array}$ & $\begin{array}{l}\text { Best } \\
\text { Next } \\
\text { Worst }\end{array}$ & $\begin{array}{l}4.0 \\
5.0 \\
2.0\end{array}$ & $\begin{array}{l}5.0 \\
4.0 \\
1.0\end{array}$ & $\begin{array}{l}1.5 \\
6.5 \\
3.0\end{array}$ & $\begin{array}{l}4.0 \\
4.5 \\
1.5\end{array}$ \\
\hline Placebo & $\begin{array}{l}\text { Best } \\
\text { Next } \\
\text { Worst }\end{array}$ & $\begin{array}{l}0.5 \\
2.5 \\
8.0\end{array}$ & $\begin{array}{l}2.0 \\
2.5 \\
5.5\end{array}$ & $\begin{array}{l}2.5 \\
2.5 \\
6.0\end{array}$ & $\begin{array}{l}2.0 \\
1.5 \\
6.5\end{array}$ \\
\hline
\end{tabular}


pleted, it transpired that $\mathrm{NH}$ emphasised the change in EMG score from the afternoon's first two (control) readings when making her assessments, while DLMcL gave more weight to the absolute levels of integrated EMG achieved during the middle $2 \mathrm{~h}$ of the recording.

\section{Shortening phase}

The activity of the drugs could also be detected in the shortening phase of the movement (table 2). The activity during this phase (which could be taken as an index of "resting muscle tone", except in the one patient who had a shortening reaction), was suppressed slightly more effectively by baclofen than by DS103-282, but the overall effect for the two drugs was similar, placebo being less effective.
DS103-282 therefore differed from baclofen in its effect upon the stretch response, but was similar in its effect upon the shortening activity and by implication upon resting tone. The effect of baclofen upon shortening activity cannot be ascribed to drowsiness, since drowsiness was more apparent with DS103-282 than with baclofen (see below).

Time course of the effect of a single dose

In order to establish a time course of the activity of the active preparations, the integrated EMG scores for each afternoon's recordings were expressed as a percentage of the control (pre-dose) readings for that afternoon. Similar results were obtained at all three repetition rates but data were
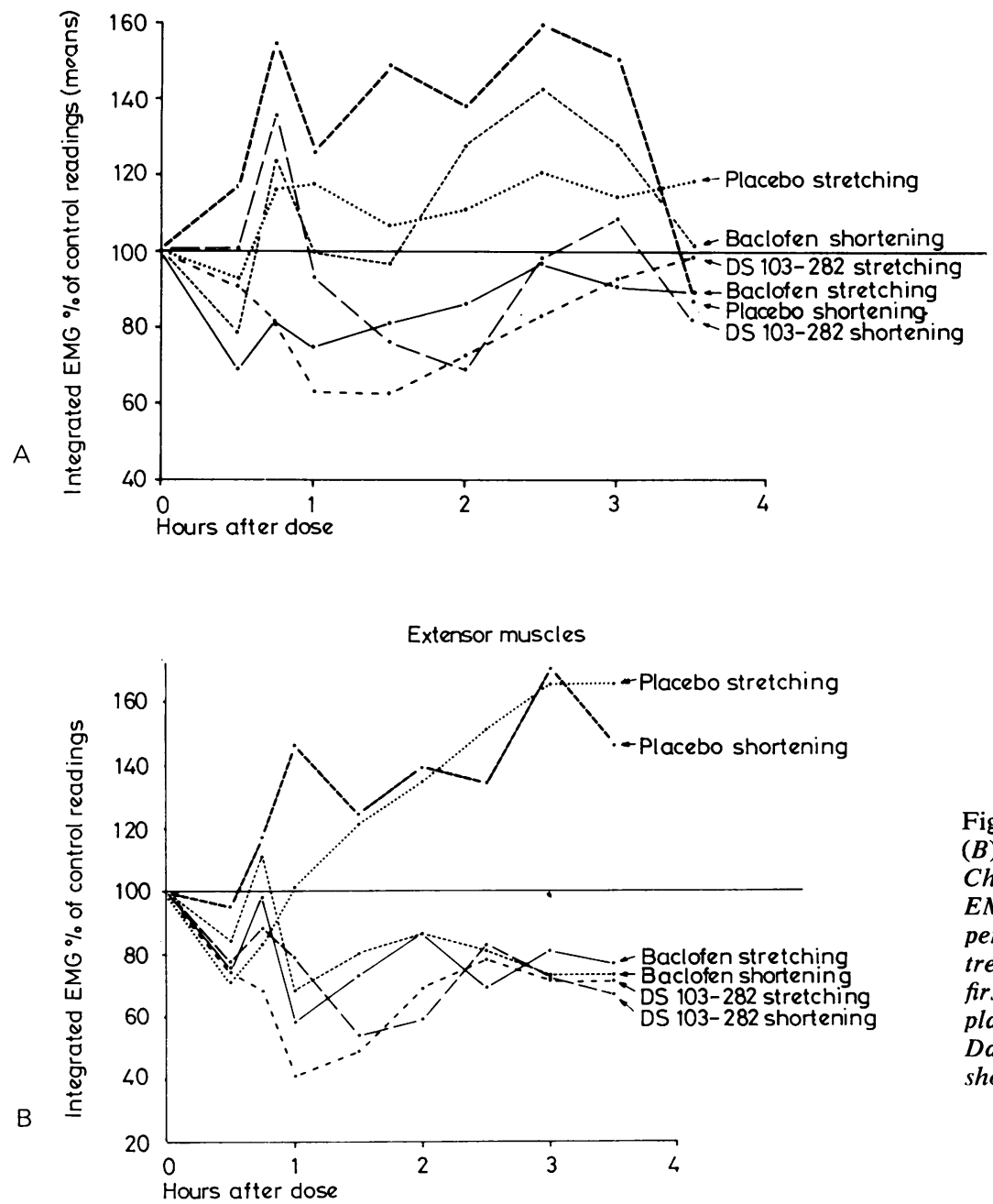

Figure $(A)$ Flexor muscles; (B) Extensor muscles. Changes in the mean integrated EMG score expressed as a percentage of control (pretreatment) score during the first $3.5 \mathrm{~h}$ after a single dose of placebo, baclofen or DS103-282. Data from lengthening and shortening phases are shown. 
most complete for $0.52 \mathrm{~Hz}$. Some patients showed little or no stretch response at $0.26 \mathrm{~Hz}$ while some developed unquantifiable spasms when moved at $0.78 \mathrm{~Hz}$. Therefore, only the results obtained at $0.52 \mathrm{~Hz}$ are presented in this section. The mean data from the 12 subjects are shown graphically in the figure (A and B), indicating that both drugs were relatively more effective in the extensor than flexor muscles. Individual data from placebo and treatment sessions were then compared, statistical analysis using the Student's paired $t$ test giving the results shown in table 3 . The effect of DS103-282 effects than baclofen or placebo, the commonest effect being drowsiness. From the patients' comments it appears that this drowsiness came on later than the peak anti-spastic effect and may therefore be due to an active metabolite. No patient received concurrent medication except one patient at his third day of attendance. Following our second day of assessment he had visited his general practitioner, who had found his blood pressure to be raised and prescribed methyldopa $250 \mathrm{mg}$ twice daily. The patient forgot to inform us of this and became hypotensive after receiving

Table 3 Statistical analysis of the difference between placebo and treatment responses, using the paired $t$ test to compare integral EMG scores. These scores were expressed as a percentage of that afternoon's control values. The mean scores are shown graphically in the figure

\begin{tabular}{|c|c|c|c|c|c|c|c|c|}
\hline \multirow{4}{*}{$\begin{array}{l}\text { Time after } \\
\text { dose }(h)\end{array}$} & \multicolumn{8}{|c|}{ Placebo compared with baclofen } \\
\hline & \multicolumn{4}{|c|}{ Flexor muscles } & \multicolumn{4}{|c|}{ Extensor muscles } \\
\hline & \multicolumn{2}{|c|}{ Passive stretch } & \multicolumn{2}{|c|}{ Passive shortening } & \multicolumn{2}{|c|}{ Passive stretch } & \multicolumn{2}{|c|}{ Passive shortening } \\
\hline & $t$ & $p$ & $t$ & $p$ & $t$ & $p$ & $t$ & $p$ \\
\hline $\begin{array}{l}0.5 \\
0.75 \\
1.0 \\
1.5 \\
2.0 \\
2.5 \\
3.0 \\
3.5\end{array}$ & $\begin{array}{l}-1.667 \\
-3.053 \\
-2.801 \\
-1.133 \\
-1.525 \\
-2.023 \\
-2.373 \\
-2.522\end{array}$ & $\begin{array}{l}\text { NS } \\
<0.02 \\
<0.02 \\
\text { NS } \\
\text { NS } \\
\text { NS } \\
<0.05 \\
<0.05\end{array}$ & $\begin{array}{l}-1.243 \\
-0.638 \\
-1.375 \\
-0.838 \\
-0.058 \\
+0.065 \\
+1.212 \\
-1.463\end{array}$ & $\begin{array}{l}\text { NS } \\
\text { NS } \\
\text { NS } \\
\text { NS } \\
\text { NS } \\
\text { NS } \\
\text { NS } \\
\text { NS }\end{array}$ & $\begin{array}{r}+0.505 \\
+0.695 \\
-1.762 \\
-1.109 \\
-1.519 \\
-1.743 \\
-1.569 \\
-1.906\end{array}$ & $\begin{array}{l}\text { NS } \\
\text { NS } \\
\text { NS } \\
\text { NS } \\
\text { NS } \\
\text { NS } \\
\text { NS } \\
\text { NS }\end{array}$ & $\begin{array}{l}-1.306 \\
-0.226 \\
-2.933 \\
-1.570 \\
-2.298 \\
-1.936 \\
-2.350 \\
-1.538\end{array}$ & $\begin{array}{l}\text { NS } \\
\text { NS } \\
<0.02 \\
\text { NS } \\
<0.02 \\
\mathrm{~N} \\
<0.05 \\
\mathrm{NS}\end{array}$ \\
\hline 3.5 & \multicolumn{8}{|c|}{ Placebo compared with DS103-282 } \\
\hline $\begin{array}{l}0.5 \\
0.75 \\
1.0 \\
1.5 \\
2.0 \\
2.5 \\
3.0 \\
3.5\end{array}$ & $\begin{array}{l}-0.142 \\
-2.003 \\
-2.591 \\
-2.702 \\
-2.149 \\
-1.701 \\
-1.267 \\
-0.431\end{array}$ & $\begin{array}{l}\text { NS } \\
\text { NS } \\
<0.05 \\
<0.02 \\
\text { NS } \\
\text { NS } \\
\text { NS } \\
\text { NS }\end{array}$ & $\begin{array}{l}-0.943 \\
-0.199 \\
-1.205 \\
-0.953 \\
-1.661 \\
-1.420 \\
-0.962 \\
-0.462\end{array}$ & $\begin{array}{l}\text { NS } \\
\text { NS } \\
\text { NS } \\
\text { NS } \\
\text { Nd } \\
\text { NS } \\
\text { NS } \\
\text { NS }\end{array}$ & $\begin{array}{l}+0.372 \\
-0.672 \\
-1.937 \\
-2.513 \\
-2.358 \\
-1.348 \\
-1.733 \\
-1.454\end{array}$ & $\begin{array}{l}\text { NS } \\
\text { NS } \\
\text { NS } \\
<0.05 \\
<0.05 \\
\text { NS } \\
\text { NS } \\
\text { NS }\end{array}$ & $\begin{array}{r}-0.865 \\
+1.507 \\
-2.530 \\
-2.538 \\
-3.672 \\
-1.388 \\
-2.200 \\
-0.976\end{array}$ & $\begin{array}{l}\text { NS } \\
\text { NS } \\
<0.05 \\
<0.05 \\
<0.01 \\
\text { NS } \\
\text { NS } \\
\text { NS }\end{array}$ \\
\hline
\end{tabular}

starts at $30-45$ min after ingestion, becoming clearly statistically significant at $1 \mathrm{~h}$, reaching a peak at $1-1.5 \mathrm{~h}$ and thereafter declining. The effect of baclofen begins at approximately the same time and lasts longer.

\section{Effect of drugs upon phase relationship of peak EMG during the stretching cycle}

The peak of the EMG response in flexor muscles at $0.52 \mathrm{~Hz}$ occurred as the angle of the joints reached approximately $128^{\circ}$, ie after $38^{\circ}$ in the $45^{\circ}$ arc of stretching. The peak EMG in the extensor muscles occurred at a joint angle of $102^{\circ}$, ie after $33^{\circ}$ in the $45^{\circ}$ arc of stretch. There was no significant change in these phase relationships during treatment with placebo or active drugs.

\section{Side effects}

The side effects reported are shown in table 4 . A single dose of DS103-282 produced more side a dose of DS103-282. There was no change in the pulse or blood pressure with either of the active preparations, except in this patient. Forty-five min after DS103-282 his blood pressure dropped to $90 / 70 \mathrm{mmHg}$ without any significant change in pulse rate, recovering gradually and spontaneously during the next $1.5 \mathrm{~h}$.

Table 4 Side effects of single doses. The patient who felt sleepy after placebo did not feel sleepy with active drugs. Both patients who felt sleepy with baclofen felt sleepy with DS103-282 also

\begin{tabular}{llll}
\hline Side effect & \multicolumn{2}{l}{ No of patients } & experiencing \\
\cline { 2 - 4 } & Placebo & Baclofen & DS10-effect \\
\hline Drowsiness & 1 & 2 & 5 \\
Dizziness & 1 & 0 & 1 \\
Hypotension & 0 & 0 & 1
\end{tabular}




\section{Discussion}

These results indicate that a single dose of $6 \mathrm{mg}$ of DS103-282 reduces muscle tone in spastic patients more effectively than a single dose of $20 \mathrm{mg}$ baclofen. This effect is achieved at the expense of some drowsiness and has partly worn off after $4 \mathrm{~h}$. Extensor and flexor muscles are both affected, extensor muscles being more effectively suppressed than flexor muscles. There is no change in the phase lead of the peak EMG response on the most stretched point, which argues against any specific action on the gamma efferent system. The EMG generated during muscle shortening is reduced concomitantly with the stretch response but the effect upon stretch responses is proportionately greater.

These observations suggest that DS103-282 could reduce stretch reflexes without necessarily weakening the limb and studies of more prolonged periods of administration are now in progress. DS103-282 should not be given to patients taking antihypertensive therapy, except under close medical supervision because of the possibility of inducing hypotension.
We thank the paitents for their co-operation, Sandoz Limited for financial support and supplies of the drugs. NH is supported by a grant from the National Fund for Research into Crippling Diseases, and the Medelec recording system was funded by the Wessex Regional Health Authority.

\section{References}

1 Ringwald E, Campion SJ, Gerstenbrand F, Lorincz A, Lorincz P, Ludin HP. Klinische Erfahungen mit einem neuartigen Myotonolytikum (DS103-282 Sandoz). Nervenarzt 1977; 48:355-8.

2 Sayers AC, Burki HR, Eichenberger E. The phamacology of 5-chloro-4-(2-imidazoline-2-ylamino)-2, 1, 3-benzothiadiazole (DS103-282), a novel myotonolytic agent. Arzmein-Forch, Drug Research 1980; 30:793-803.

3 McLellan DL, Selwyn M, Cooper IS. Time course of Clinical and Physiological effects of stimulation of the cerebellar surface in patients with spasticity. J Neurol Neurosurg Psychiat 1978; 41: $150-60$. 